\title{
QUAIS SÃO OS FATORES QUE INFLUENCIAM NPS DO PROGRAMA DE MESTRADO PROFISSIONAL DE GESTÃO E NEGÓCIOS DA UNISINOS
}

\author{
WHAT ARE THE FACTORS THAT INFLUENCE NPS OF THE UNISINOS \\ PROFESSIONAL MANAGEMENT AND BUSINESS MASTERS PROGRAM
}

\author{
Alessandro Fernandes ${ }^{1}$ \\ Fabiano Carpes ${ }^{2}$ \\ Cristiano Elias Melzer ${ }^{3}$ \\ Luiz Felipe Terres Ballardim ${ }^{4}$ \\ Sérgio Luiz Batistella Zambonato ${ }^{5}$
}

RESUMO: O presente trabalho buscou analisar os fatores que podem exercem influência sobre o índice de Net Promoter Score - NPS das turmas de Mestrado Profissional em Gestão e Negócios da Universidade do Vale do Rio dos Sinos - UNISINOS, que tiveram início de seus estudos no primeiro semestre de 2019, partindo de uma metodologia quantitativa, aplicando o questionário padrão NPS, com questões complementares. O estudo foi precedido por um referencial teórico que abordou organização de marketing, qualidade em serviços, lealdade do consumidor e conceitos de NPS, incluindo sua crítica. Os resultados explicitaram o impacto que um consumidor detrator sobre o índice final.

Palavras-chave: Consumidor. Detrator. Promotor.

ABSTRACT: The present work sought to analyze the factors that may influence the Net Promoter Score - NPS index of the Professional Master's classes in Management and Business at the University of Vale do Rio dos Sinos - UNISINOS, which started their

\footnotetext{
${ }^{1}$ Mestre em Gestão em Negócio pela Universidade do Vale do Rio dos Sinos, Pós-Graduando em MBA em Direito do Agronegócio pela Faculdade Legale, Pós-Graduação Lato Sensu em Gestão de Risco e Cibersegurança pela Faculdade Focus, Pós-Graduação Lato Sensu em Lei Geral de Proteção de Dados pela Faculdade Legale, Pós-Graduação Lato Sensu em História da Guerra pela Faculdade Venda Nova do Imigrante, Pós-Graduação Lato Sensu em Educação em Direitos Humanos pela Universidade Federal de Rio Grande, Pós-Graduação Lato Sensu em Direito Público para Faculdade Legale, Pós-Graduação Lato Sensu em Gestão Pública Municipal pela Universidade Federal de Rio Grand, Pós-Graduação Lato Sensu em Inovação e Empreendedorismo em Negócios Sustentáveis pelo Instituto Federal de Mato Grosso, Pós-Graduação Lato Sensu em Compliance pela Faculdade Venda Nova do Imigrante, Pós-Graduação Lato Sensu em Gestão Estratégica em Políticas Públicas pela Universidade Estadual de Campinas, MBA em Agronegócios pela Faculdade UniCesumar, Pós-Graduação Lato Sensu em Direito Empresarial pela Universidade do Vale do Rio dos Sinos, Bacharel em Ciências Jurídicas e Sociais pela Universidade do Vale do Rio dos Sinos, cursando Licenciatura em História pela Universidade Federal de Pelotas.

${ }^{2}$ Mestre em Gestão em Negócio pela Universidade do Vale do Rio dos Sinos, MBA Executivo em Gestão de Negócios do Desenvolvimento Regional Sustentável pela Universidade Federal de Mato Grosso, Graduado em Matemática pela Universidade do Vale do Rio dos Sinos.

${ }^{3}$ Mestre em Gestão em Negócio pela Universidade do Vale do Rio dos Sinos, Pós-Graduação Lato Sensu em Gestão de Negócios pela Universidade Luterana do Brasil, Graduado em Administração pela Universidade Federal do Rio Grande do Sul.

${ }^{4}$ Mestre em Gestão em Negócio pela Universidade do Vale do Rio dos Sinos, Pós-Graduação Lato Sensu em Gestão Financeira pela Universidade de Caxias do Sul, Graduado em Administração pela Universidade de Caxias do Sul.

5 Mestre em Gestão em Negócio pela Universidade do Vale do Rio dos Sinos, Pós-Graduação Lato Sensu em Administração: Gerência de Serviços pela Universidade Federal de Santa Maria, MBA executivo em Negócios Financeiros pela Fundação Getúlio Vargas, Graduado em Administração pela Universidade Federal de Santa Maria.
} 

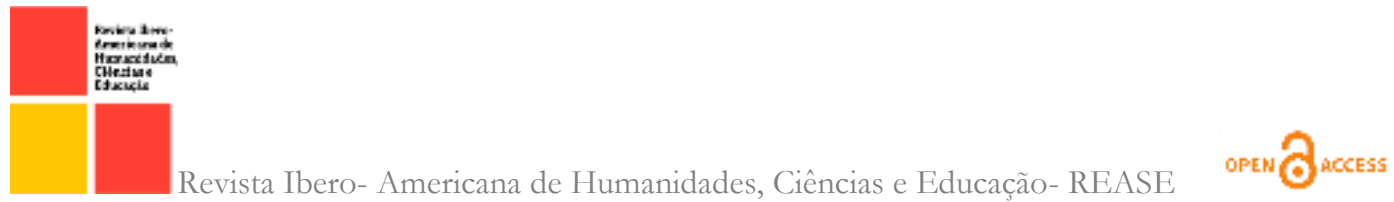

studies in the first semester of 2019, starting from a quantitative methodology, applying the standard questionnaire NPS, with complementary questions. The study was preceded by a theoretical framework that addressed marketing organization, quality of services, consumer loyalty and NPS concepts, including their criticism. The results made explicit the impact that a consumer detractor on the final index.

Keywords: Consumer. Detractor. Promoter.

\section{INTRODUÇÃO}

Identificar e melhorar a experiência do cliente tem sido uma das grandes preocupações das empresas nos últimos anos. Para tanto, Reichheld (20II) nos afirma que a única forma de saber se uma empresa está cumprindo sua missão e melhorando a vida das pessoas é mensurar sistematicamente o relacionamento com seus clientes.

Em especial na última década, independentemente do segmento da empresa, produto fabricado ou serviço prestado, a orientação para o cliente é premissa básica para o sucesso, de forma que a busca por uma métrica que possa clarear aos gestores se seus negócios estão no caminho certo ficou mais latente.

Prahalad e Krishnan (2008) mostram que a criação de valor e o crescimento de todos os negócios dependerão de uma visão mais apurada sobre as experiências singulares dos clientes. Quando os consumidores experimentam o produto, personalizam a experiência de acordo com necessidades e desejos singulares.

A própria transformação das formas de comunicação a partir da disseminação da internet e em especial das redes socias, permitiu cada vez mais se atentar para as pessoas que ainda não tinham influência sobre o sucesso de um produto ou serviço. Neste meio e com a velocidade que a comunicação e informação estão sendo disseminadas, é muito benéfico para uma empresa ter um cliente que a promova perante seu circulo de influência, bem como os estragos podem ser gigantescos se o número de clientes que possam denegrir seus produtos ou serviços for elevado.

Neste contexto, em 2003, Fred Reichheld, escreveu o artigo The One Number You Need to Grow (O número de que você precisa para crescer), sobre a conversão de clientes em promotores, que marca a criação do NPS (Net Promoter Score). Passando por temas como lealdade e crescimento, assim como o perigo dos detratores, ele nos expõe como esses, promotores e detratores, se relacionam para contribuir ou denegrir a reputação de uma empresa. $O$ indicador busca induzir, por meio da melhoria contínua da satisfação e do 
relacionamento com o cliente, o aumento de percentual de clientes promotores da marca e a redução dos detratores da marca. O cultivo de clientes promotores melhora a reputação da empresa, tornando-a mais sólida, competitiva e sustentável, uma vez que a propagação positiva da marca da empresa é feita de forma espontânea pelos consumidores muito satisfeitos.

Os mais variados setores estão aderindo a métrica do NPS: bancos, grandes varejistas, prestadores de serviços, indústria automobilística, etc. Pode-se usar como exemplos grandes corporações, desde de empresas tradicionais e centenárias no mercado, como o Banco do Brasil, assim como empresas mais jovens como o Netflix e Amazon.

O setor de educação superior não pode passar incólume a esse processo, em especial por enfrentar desafios particulares com a educação a distância e novas formas de ensino. Possuir clientes que promovam sua marca, permitindo que se mantenha a demanda e proporcione viabilidade inclusive financeira para as instituições é primordial.

Diante desse cenário, esse artigo procura fazer a ligação entre a teoria apresentada e a prática da realização de pesquisa sobre o Net Promoter Score - NPS com os alunos das turmas iniciadas no ano de 2019 do Mestrado Profissional em Gestão e Negócios da Universidade do Vale do Rio dos Sinos - Unisinos, verificando os fatores que influenciam o mesmo, bem como as possíveis limitações e críticas a essa ferramenta.

\section{REFERENCIAL TEÓRICO}

\subsection{Organização de Marketing}

A organização de marketing é a interface entre a empresa e seu mercado, e é onde o trabalho de marketing se desenvolve. (MOORMAN; DAY, 20I6). Estes autores afirmam que os 4 elementos da organização de marketing e sua integração contribuem para a excelência de marketing. Os quatro elementos são: que são capacidades organizacionais, configuração, capital humano e cultura.

Estes elementos são mobilizados pelas 7 atividades de marketing (7as), que são: antecipar-se às mudanças no mercado; adaptar a empresa a essas mudanças; alinhar processos, estruturas e pessoas; ativar comportamentos individuais e organizacionais eficientes e eficazes; criar responsabilidade pelo desempenho de marketing; atrair recursos financeiros, humanos e outros recursos importantes; e se engajar no gerenciamento de ativos que desenvolvem e implementam ativos de marketing, conforme Figura I. 
As 7 atividades possibilitam que a empresa se antecipe às mudanças do mercado, adapte a estratégia e se mantenha à frente dos competidores, alinhando a organização à estratégia e ao mercado, ativando sua efetiva implementação e assegurando os resultados e atraindo recursos.

Figura I- Marketing Organization and Firm Performance.

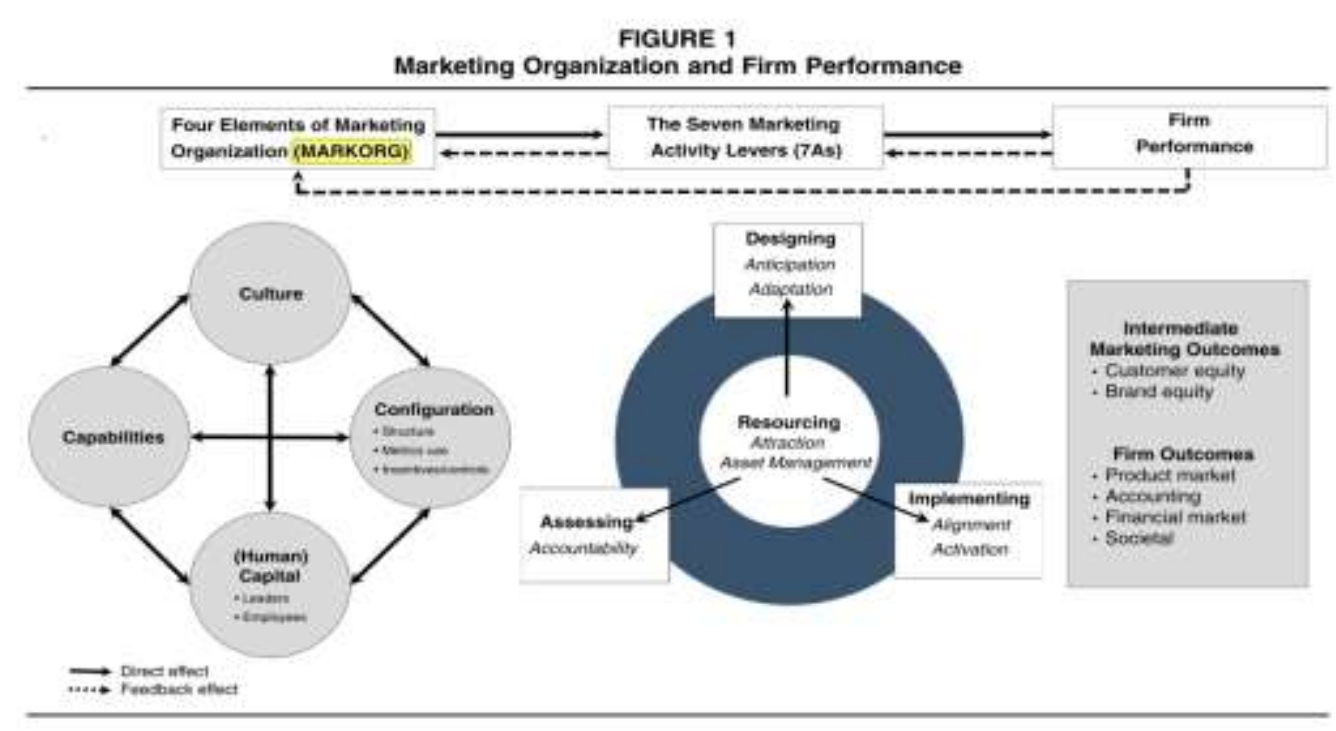

Fonte: (MOORMAN; DAY, 2016).

\subsection{Qualidade em serviços}

Berry (1996) menciona que a qualidade é definida pelo cliente. A conformidade com as especificações da empresa não é qualidade; a conformidade com as especificações do cliente é qualidade.

Os estudos de qualidade de serviços tem como referência os autores Parasuraman, Zeithaml e Berry que consideram que a qualidade do serviço é medida pelo GAP entre a expectativa e a qualidade percebida pelo consumidor (PARASURAMAN; ZEITHAML; BERRY, 1985). Os autores desenvolveram o modelo ServQuali, para medir a qualidade de serviços. Identificaram 5 Gaps ou lacunas que determinam a qualidade se serviço, sendo o gap 5, diferença entre o serviço esperado e o serviço percebido pelo consumidor, uma função resultante dos demais gaps.

- GapI - expectativas do consumidor X percepção dos gestores;

- Gap2 - percepção dos gestores X especificação da qualidade;

- Gap3 - especificações de qualidade X entrega de serviços;

- Gap 4 - entrega de serviço X comunicação externa; 
- Gaps - serviço esperado X percebido.

O modelo se baseia em ıo determinantes da qualidade de serviço resumidos a seguir:

- Tangibilidade: se refere às evidências físicas do serviço;

- Confiabilidade: cumprir o que foi prometido na primeira vez;

- Responsividade: capacidade de atender prontamente com flexibilidade para adaptar o serviço às necessidades do cliente;

- Competência: possuir as habilidades e conhecimentos para entregar o serviço;

- Cortesia: polidez, respeito cortesia no trato pessoal;

- Credibilidade: confiabilidade, credibilidade e honestidade;

- Segurança: ausência de perigo, risco ou dúvida;

- Acesso: acessibilidade e facilidade de contato;

- Comunicação: manter o consumidor informado em linguagem acessível;

- Entendendo o cliente: esforçar-se para entender as necessidades do cliente.

\subsection{Lealdade do consumidor}

Em estudo recente, Shahsavar e Sudzina apresentam o conceito de lealdade no contexto do ensino superior de Webb e Jagun como a disposição do aluno em recomendar a instituição a outros, o desejo de dizer coisas positivas sobre a instituição e seu retorno à instituição para continuar seus estudos. Trazem ainda a opinião de Athiyaman sobre lealdade, que é a combinação entre a disposição dos alunos de falar positivamente sobre a instituição e de fornecer informações aos novos candidatos (SHAHSAVAR; SUDZINA, 2017).

Em sua pesquisa Shahsavar e Sudzina testaram os efeitos da imagem da universidade, das expectativas dos alunos, da qualidade percebida do software, da qualidade percebida do hardware e do valor percebido na satisfação. Concluíram que a imagem da universidade, a qualidade percebida do software e a satisfação têm efeitos sobre a lealdade. A definições no contexto do ensino superior apresentada pelos autores para software ou human ware inclui elementos humanos como ensino, padrão acadêmico, métodos pedagógicos e contato pessoal com a equipe de ensino administrativa. A definição de hardware inclui elementos não humanos como programas de estudo e cursos fornecidos 
e funções de suporte (salas de aula, biblioteca, instalações de informática, equipamentos, áreas para estudantes etc.)

\subsection{NPS - Net Promoter Score}

Em 2003 Reichheld publicou um artigo na Harvard Business Review em que ele afirmava que o Net Promoter Score - NPS (introduzido por ele), é o único número que você precisa para crescer e o único número que você precisa para gerenciar a fidelidade do cliente.

A metodologia NPS é bastante simples, baseado na pergunta: "Em uma escala de o a Io, o quanto você indicaria nossa empresa para um amigo ou parente?” é possível avaliar se o cliente é promotor, passivo ou detrator da marca observando sua resposta. (REICHHELD, 2008).

\subsection{O modelo NPS}

Baseado em uma escala do tipo Likert de il pontos, onde io representa "extremamente propenso", 5 representa "neutro" e o representa "extremamente não propenso". O autor identifica 3 categorias de consumidores pela sua intenção de recompra. A primeira é de "promotores" que consiste dos consumidores que indicaram os pontos $9 \mathrm{e}$ ı. A segunda Categoria é dos "neutros", que indicaram os pontos 7 e 8 . A terceira categoria é a dos "detratores", que indicaram os pontos de o a 6.

Segundo (REICHHELD, 2004), a intenção do consumidor recomendar a empresa para amigos resulta de como ele foi tratado pela linha de frente de empregados, que por sua vez, é determinado pela contribuição de todas as áreas funcionais que contribuem para a experiência do cliente.

A metodologia vem sendo aplicada por um número cada vez maior de empresas, basicamente pela sua simplicidade.

O conceito de lealdade apresentado por (REICHHELD, 2004) é "a disposição de alguém, um cliente, um funcionário, um amigo, de fazer um investimento ou sacrifício pessoal, a fim de fortalecer um relacionamento." O autor sustenta que a lealdade dos clientes claramente afeta a lucratividade da empresa. 


\subsubsection{Críticas ao NPS}

A simplicidade do NPS é ao mesmo tempo sua principal virtude e o maior motivo de críticas. Se por um lado o NPS pode ser mais efetivo para promover mudanças culturais por ser fácil de explicar (BENDLE; BAGGA; NASTASOIU, 2019), por outro lado, não identifica os motivos da promoção ou detração. A mesma crítica é referida por (ZAKI et al., 2016), Embora a medida NPS possa ser usada como um indicador de fidelidade, ela não oferece uma explicação da causa principal ou das causas de uma pontuação baixa. Dizem ainda que a fidelidade do cliente é multidimensional e assim, ferramentais melhores são necessários.

(BENDLE; BAGGA; NASTASOIU, 2019) apresentam outras críticas ao modelo, como por exemplo:

- o NPS é popular por que é popular. O uso do NPS realimenta sua popularidade e alguns executivos adotam o NPS em suas empresas porque outros executivos já adotam;

- o NPS está ligado à lucratividade, quando na verdade mede a intenção de recompra;

- a falha em focar às variáveis dependentes leva ao envio de mensagens confusas aos gerentes.

Uma lista de críticas ao NPS é apresentada por (FISHER; KORDUPLESKI, 2019) para executivos e administradores:

- O NPS não fornece dados sobre o que fazer para melhorar;

- NPS concentra-se apenas em manter os clientes, não em ganhar novos clientes;

- Não existe um cliente "passivo";

- O NPS não fornece dados sobre competição;

- O NPS está focado internamente e não externamente."

Outros modelos de medição de fidelidade foram propostos, como a American Customer Satisfaction Index (CCSI) e seu correspondente europeu (EPSI) que tem sido aceitos como boas soluções, segundo (KRISTENSEN; ESKILDSEN, 20II).

Os autores (KRISTENSEN; ESKILDSEN, 20II) afirmam que o NPS é uma medida ineficiente e não confiável de fidelidade do cliente sendo muito inferior às medidas padrão de fidelidade usada pela Classificação ACSI e EPSI. Os autores ressaltam que a 
medida de predição de crescimento não é necessariamente uma única medida, e que variáveis demográficas e diferenças culturais podem afetar o uso da escala. Alegam também a falha na sustentação de causa e efeito entre o NPS e performance financeira devido a aplicação de método estatístico insuficiente e rudimentar. Por fim afirmam que o NPS não sobrevive aos critérios da $\mathrm{ABPN}$, (que são validade, confiabilidade, robustez, contexto estrutural e relevância), sendo rejeitado por ser inválido, não confiável e não robusto.

\section{Metodologia}

Para a realização do trabalho, foi realizada pesquisa do NPS complementada com questões complementares e com a possibilidade de identificação dos respondentes.

O público da pesquisa foram todos os alunos do Mestrado Profissional em Gestão e Negócios da UNISINOS que iniciaram seus estudos em 2019-I, das turmas regulares com módulo Internacional ${ }^{6}$, da turma formada por gerentes do Banco do Brasil e ainda da turma formada por funcionários vinculados ao Sistema de Cooperativas de Crédito (Sicredi, Unicred, Siscob, entre outros) num total de 75 alunos. O link para a participação na pesquisa foi remetido pela secretaria do curso, por e-mail, para todos os alunos, e a solicitação de resposta foi reforçada pelos líderes das turmas via grupo de whatsapp. 49 alunos (65,3\% dos consultados) responderam à pesquisa, distribuídos conforme expresso na figura 2:

Figura 2- Distribuição dos Respondentes por Turmas

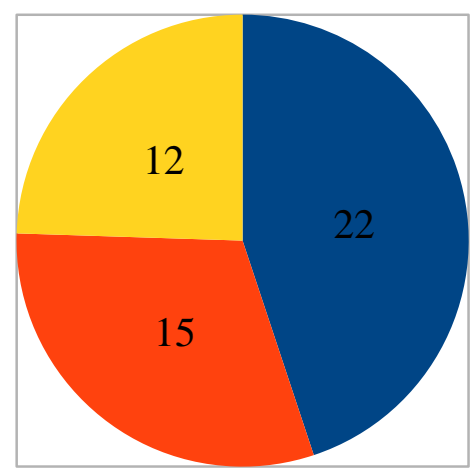

- Turma Banco do
Brasil
Turma
Cooperativas
Turma
Internancional

A coleta de dados da pesquisa foi realizada pelo app Survey Monkey ${ }^{7}$. Em função do pequeno número de respondentes, não cabem maiores tratamentos estatísticos.

6 Esta turma oferece a dupla titulação, realizada na Universidade de Poitiers (França) e já incluída no investimento do Programa, contando com disciplinas ministradas por professores estrangeiros.

7 App for IOS, versão 2.0.91. 
Foi feita análise de conteúdo das entrevistas. Em função de somente um dos respondentes acabar identificado com as características de detrator ficou prejudicado a análise de suas razões, um dos objetivos iniciais do trabalho.

\section{RESULTADOS}

Da análise da pesquisa coletou-se os seguintes dados referente ao NPS do Mestrado Internacional da UNISINOS.

Figura 3- NPS Mestrado Profissional Gestão em Negócios

$\%$ de Promotores

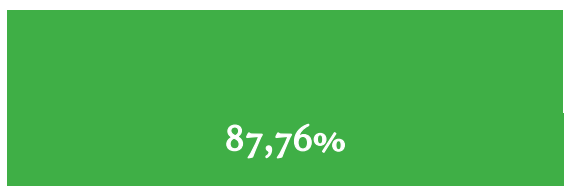

$\%$ de Neutros

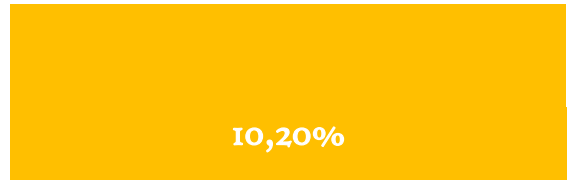

$\%$ de Detratores

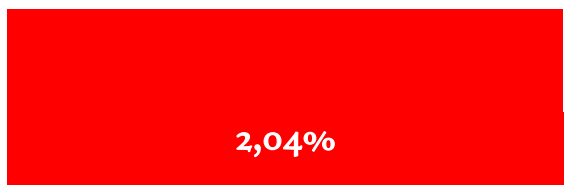

Quantidade de Promotores

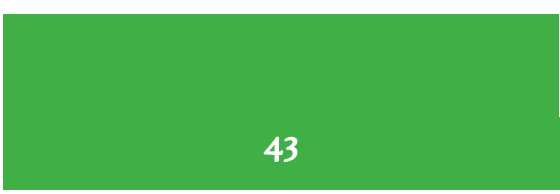

Quantidade de Neutros

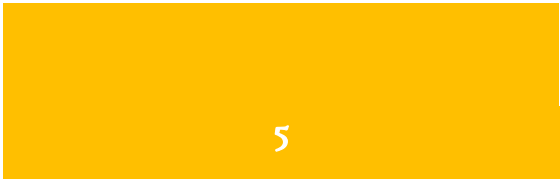

Quantidade de Detratores

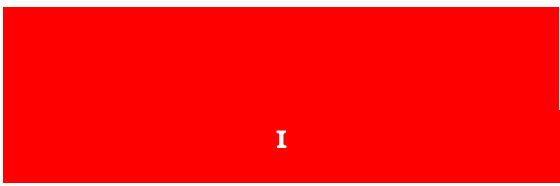

NPS

$85,71 \%$

\section{Zona de}

Excelência ${ }^{8}$

Não verificamos grandes variações dos valores de NPS quando dividimos a pesquisa por turmas, excetuado a turma cooperativas, a única em que identificamos um detrator. Este único dado foi suficiente para deslocar a nota NPS da avaliação da zona de excelência para zona logo abaixo, a zona de qualidade. Os dados individualizados podem ser melhor notados pelas figuras 4,5 e 6 , que seguem abaixo:

Figura 4- NPS Mestrado Profissional Gestão em Negócios - Turma Internacional

$\%$ de Promotores

$90,91 \%$
Quantidade de Promotores

NPS
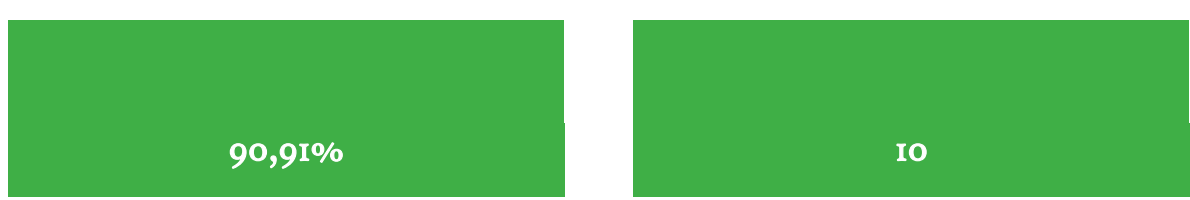

$90,91 \%$

8 Zona de Excelência é quando a nota do NPS se encontra entre 75 e Ioo, numa escala que vai de -Ioo a 100. 
$\%$ de Neutros

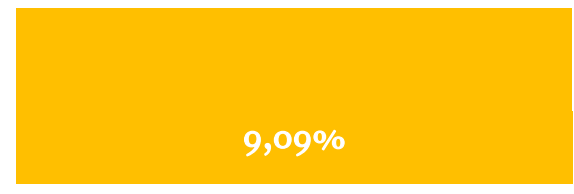

$\%$ de Detratores

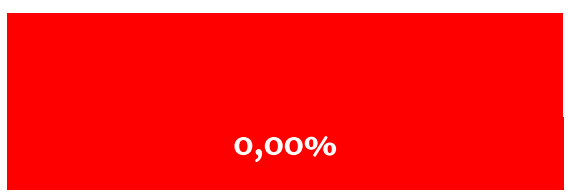

Quantidade de Neutros

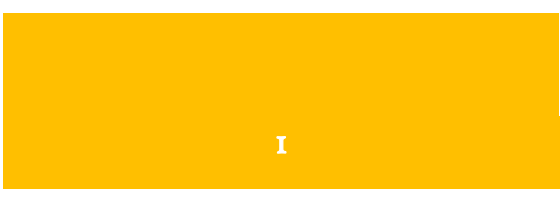

Quantidade de Detratores

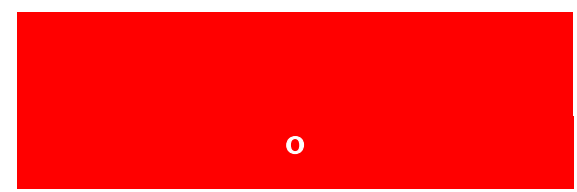

Zona de

Excelência

Figura 5- NPS Mestrado Profissional Gestão em Negócios - Turma Banco do Brasil

$\%$ de Promotores

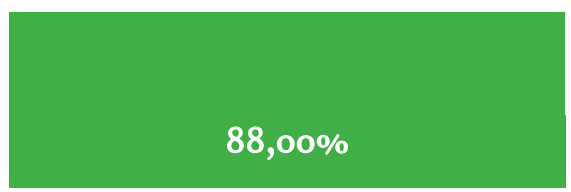

$\%$ de Neutros

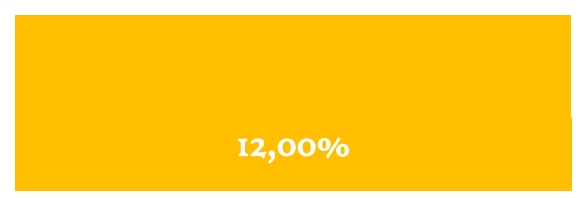

$\%$ de Detratores

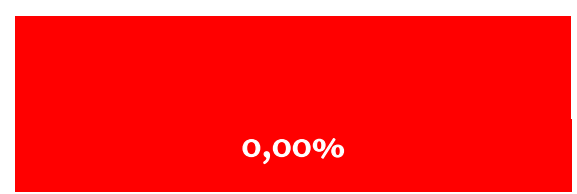

Quantidade de Promotores

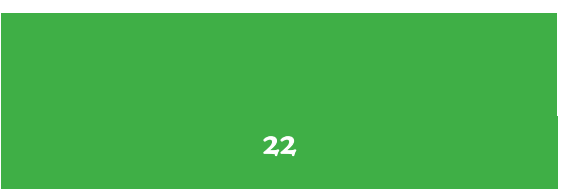

Quantidade de Neutros

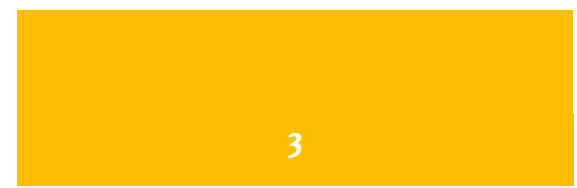

Quantidade de Detratores

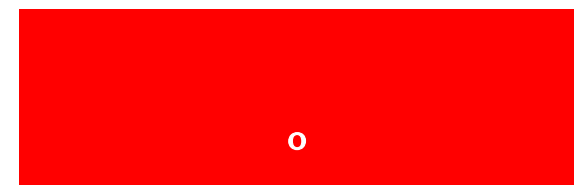

Figura 6- NPS Mestrado Profissional Gestão em Negócios - Turma Cooperativas

$\%$ de Promotores

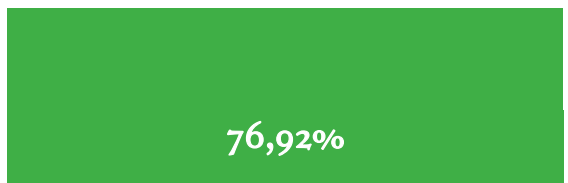

$\%$ de Neutros

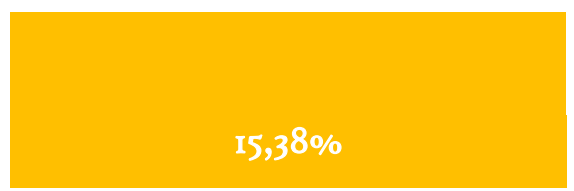

$\%$ de Detratores
Quantidade de Promotores

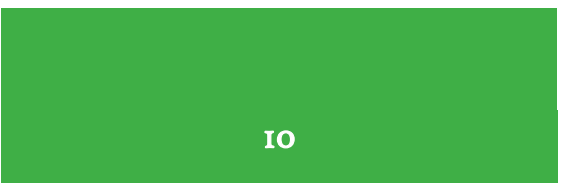

Quantidade de Neutros

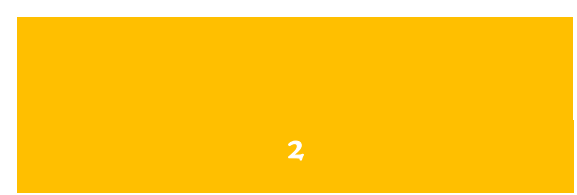

Quantidade de Detratores
NPS

$88,00 \%$

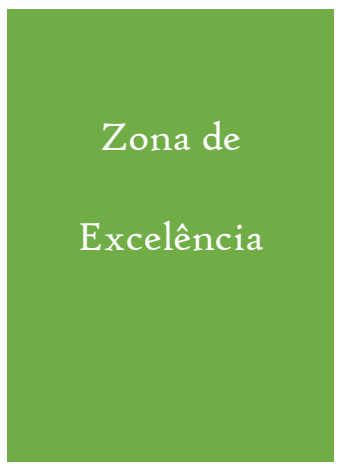

NPS

$69,14 \%$

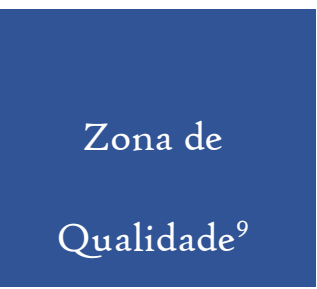

9 Zona de Qualidade é quando a nota do NPS se encontra entre so e 75, numa escala que vai de -roo a 100. 

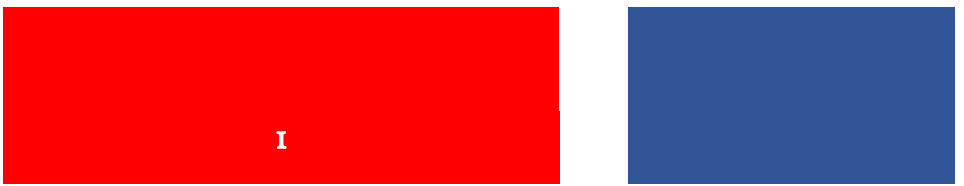

Dos alunos que responderam aos questionamentos apresentados, um deles tratava de questionar se o aluno já teria alguma experiência anterior na UNISINOS, seja na Graduação ou em um dos variados Programas de Pós-Graduação, e percebeu-se que I9 respondentes já haviam cursado a Universidade, conforme dados abaixo:

Figura 7- Alunos Egressos UNISINOS

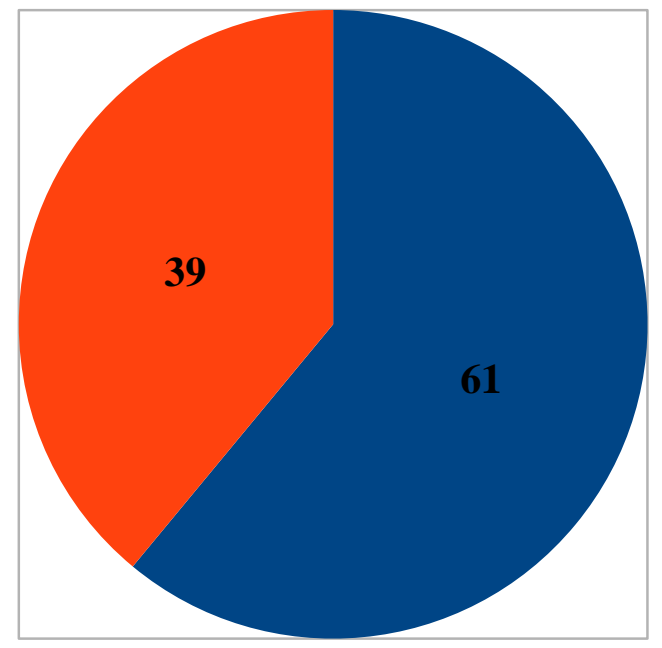

- Não Egressos

- Egressos UNISNOS

Este grupo é composto exclusivamente por promotores, com 100\% das respostas entre 9 e io.

Figura 8- NPS Mestrado Profissional Gestão em Negócios - Alunos Egressos UNISINOS

$\%$ de Promotores

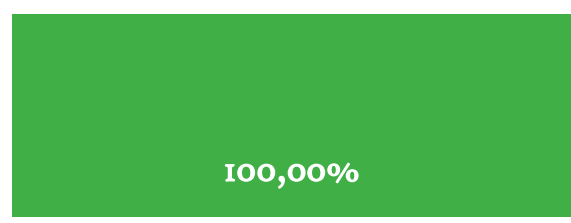

$\%$ de Neutros

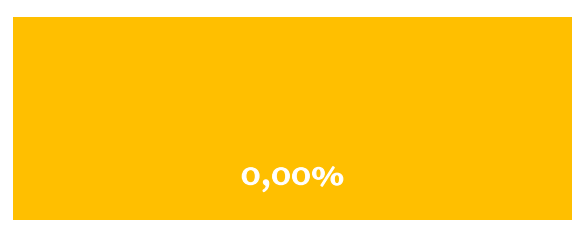

\% de Detratores
Quantidade de Promotores

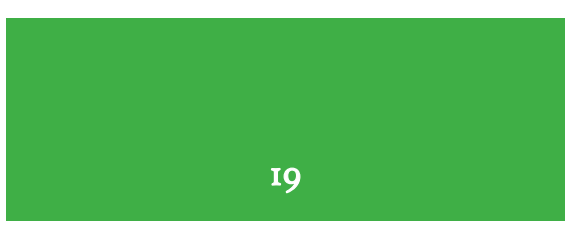

Quantidade de Neutros

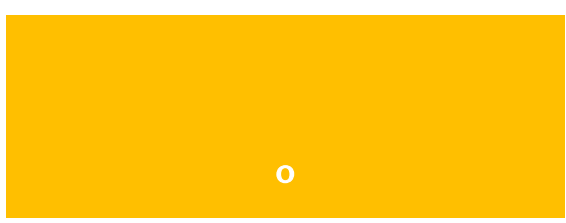

Quantidade de Detratores
NPS

$100,00 \%$ 

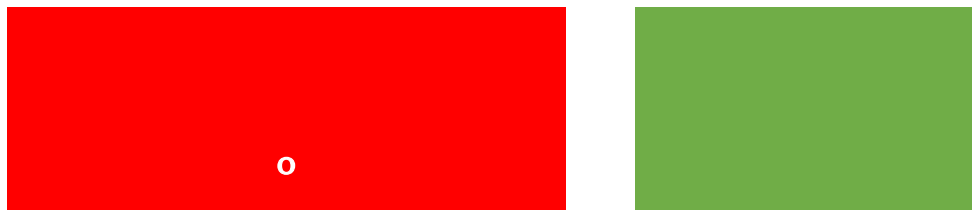

\section{CONCLUSÃO}

Pesquisadores educacionais e gerentes de universidades devem classificar fatores influentes satisfazer a satisfação e a lealdade com base em sua importância no ambiente atual e alocar recursos para melhorar a posição da universidade no mercado competitivo do ensino superior, a fim de atrair mais fundos e estudantes. Além disso, identificar as demandas dos alunos e atendê-las é essencial para tornar os alunos satisfeitos e leais e se tornar líderes no mercado de ensino superior. (SHAHSAVAR; SUDZINA, 2017).

Pelos resultados apurados o equívoco do trabalho foi buscar analisar o perfil dos detratores, quando o público que aparenta merecer maior atenção são os neutros, uma vez que somam um número superior a $10 \%$, cinco vezes superior ao índice de detratores, mesmo que sua simples existência tenha tido um grande impacto na nota NPS, como pode ser bem visualizado quando individualizamos as notas por turmas.

Mesmo assim, parece-nos que este público composto pelos "neutros" deve ser aonde a UNISINOS deve dedicar maior atenção, principalmente por sua maior incidência que os detratores. As formas de conversão dos neutros em promotores no programa poderão servir de campo para novos estudos.

\section{REFERÊNCIAS}

BENDLE, N. T.; BAGGA, C. K.; NASTASOIU, A. Forging a Stronger AcademicPractitioner Partnership-The Case of Net Promoter Score (NPS). Journal of Marketing Theory and Practice, v. 27, n. 2, p. 210-226, 2019.

FISHER, N. I.; KORDUPLESKI, R. E. Good and bad market research: A critical review of Net Promoter Score. Applied Stochastic Models in Business and Industry, v. 35, n. I, p. 138-151, 2019.

KRISTENSEN, K.; ESKILDSEN, J. Is the Net Promoter Score a reliable performance measure? 201r IEEE International Conference on Quality and Reliability, ICQR 201r, p. 249-253, 2011.

MOORMAN, C.; DAY, G. S. Organizing for marketing excellence. Journal of Marketing, v. 8o, n. 6, p. 6-35, 2016. 
PARASURAMAN, A.; ZEITHAML, V. A.; BERRY, L. L. A conceptual model of service quality and its implications for future research. Journal of Marketing, v. 49, n. 4, p. 4I-50, 1985.

PRAHALAD, C K., KRISHNAN, M S.. A Nova Era da Inovação: A Inovação focada no Relacionamento com o Cliente. Rio de Janeiro, Elsevier, 2010.

REICHHELD, F. F. The one number you need to grow. Harvard Business Review, v. 82, n. 6, p. 133, 2004 .

REICHHELD, Frederick. A Pergunta Definitiva 2.o - Como as empresas que utilizam o Net Promoter Score prosperam em um mundo voltado aos clientes. Rio de Janeiro, p.3, Elsevier, 20II.

SHAHSAVAR, T.; SUDZINA, F. Student satisfaction and loyalty in Denmark: Application of EPSI methodology. PLoS ONE, v. I2, n. I2, p. I-19, 2017.

ZAKI, M. et al. The Fallacy of the Net Promoter Score: Customer Loyalty Predictive Model. Cambridge Service Alliance, n. October 2016, p. I-26, 2016. 